\title{
Dos retratos firmados por el pintor José Gil de Castro
}

Jaime Mariazza Foy

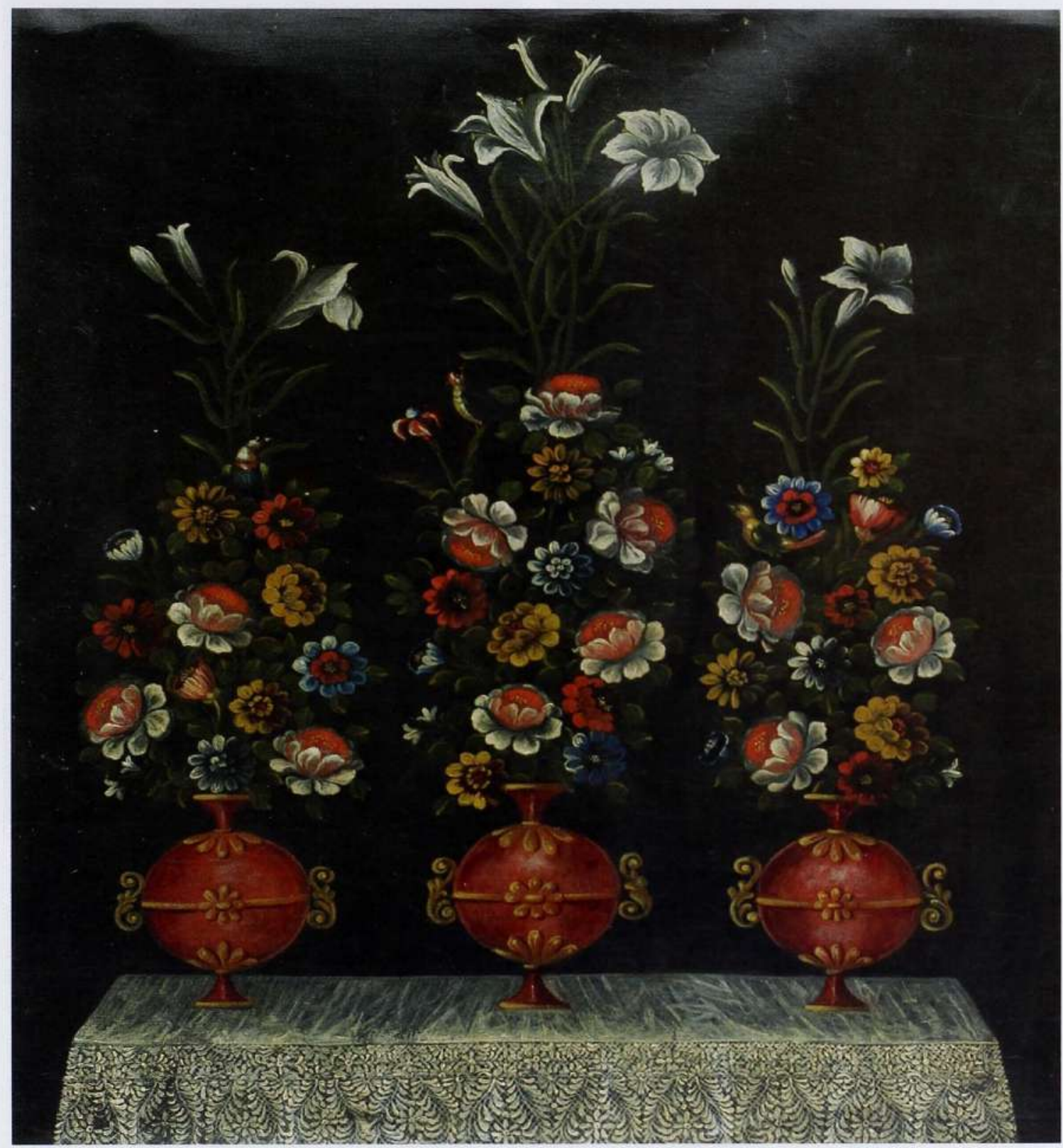

Fig.1. Lienzo moderno con flores ornamentales

Procedentes de una incautación por exportación irregular, se tiene dos lienzos pintados con flores en tonos rosa iridiscente, blanco y gris dentro de floreros globulares azules, en uno, y rojos, en el otro, similares a los que suelen adornar las imágenes coloniales del Cristo de los Temblores. En estos lienzos, el cromatismo de flores y floreros contrasta aun más por el fondo negro sobre el que están hechos (Fig.1). Fueron etiquetados como pinturas del siglo XVIII y enviados a los laboratorios del Ministerio de Cultura para evaluar 


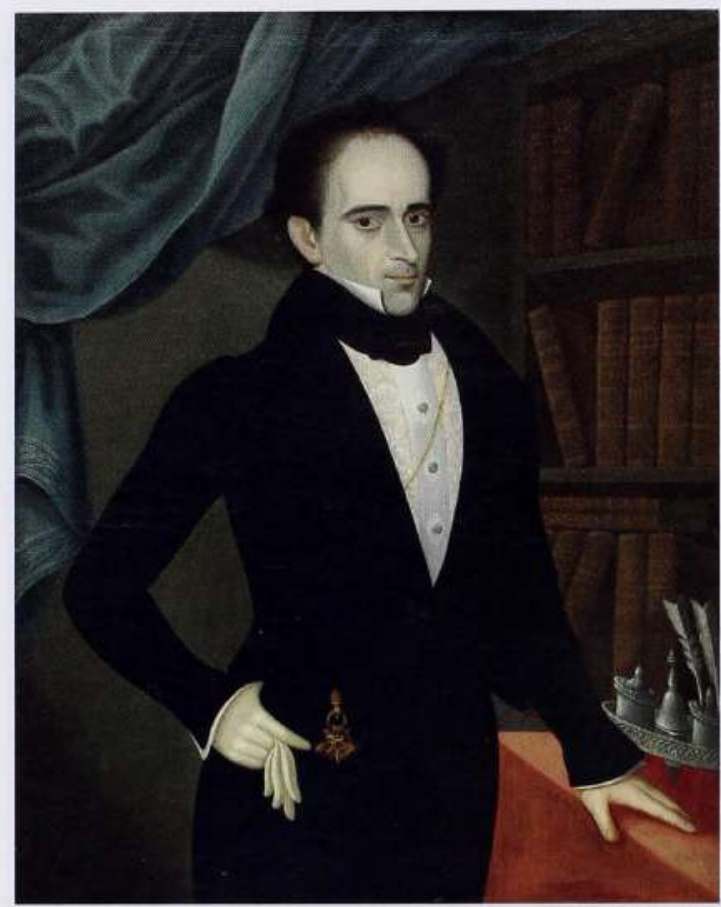

Fig. 2. Don Francisco de Mendoza Ríos y Caballero. Pintado por José Gil de Castro. 1837

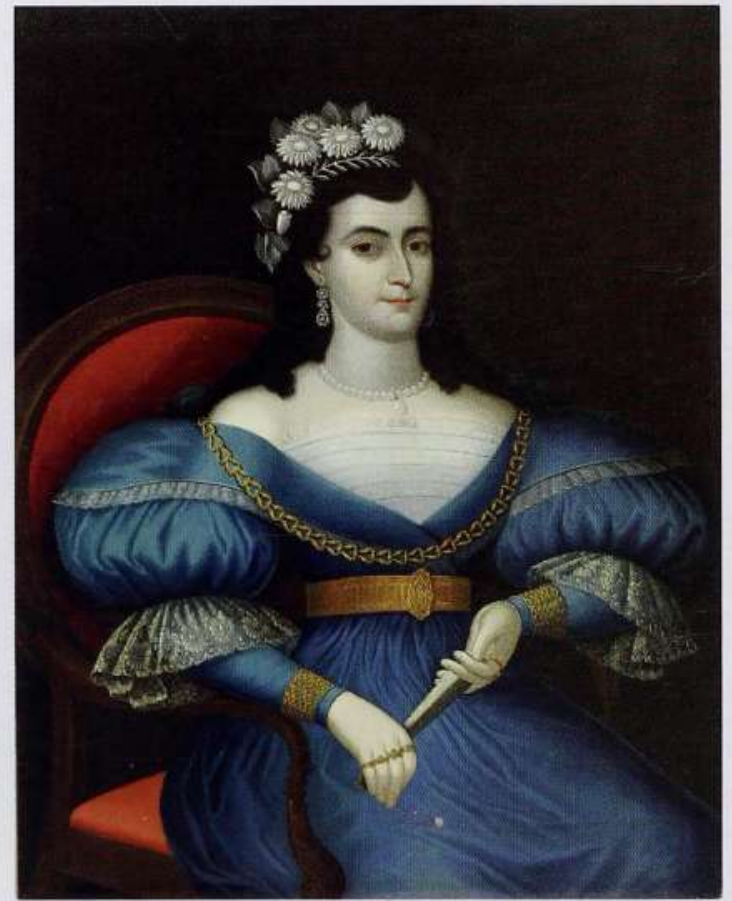

Fig. 3. Manuela Boza y Carrillo de Albornoz. José Gil de Castro. 1837.

su estado de conservación. Una mirada atenta a tales cuadros determinó la existencia de ciertos rasgos que ponían en duda su originalidad. Entre otros, el craquelado artificial que lucían y la diferencia de tejido entre el anverso y el reverso de las telas, factores que fueron determinantes para emprender un análisis minucioso de las dos obras. Un examen químico de los pigmentos concluyó que la base de preparación en ambos casos contenía elementos aglutinados con temple sintético. La capa pictórica estaba constituida principalmente por blanco de titanio, azul de ultramar sintético y rojo compuesto de blanco de titanio y rojo cadmio con laca roja sintética. Eran, por tanto, telas pintadas recientemente y no en el siglo XVIII, como se asegura en los documentos oficiales.

Al ser desmontadas de sus respectivos bastidores, se constató que bajo cada tela pintada con flores había otra que contenía un retrato de características decimonónicas en cuyo reverso se adhirió una tela impregnada con cera. Ésta tenía como propósito, en cada caso, ocultar una cartela ovalada donde se lee los nombres de los retratados y la firma del pintor. Al momento de su examen, estas cubiertas habían perdido ya adherencia por lo que pudieron ser retiradas con facilidad sin afectar el pigmento de la caligrafía.

Los retratos ocultos eran los de Francisco de Mendoza Ríos y Caballero, alcalde de Lima en cuatro periodos, y el de su mujer, Manuela Boza y Carrillo de Albornoz de Mendoza (Figs. 2 y 3). Su autor es el pintor José Gil de Castro cuya firma aparece en la parte baja de las cartelas ovaladas, situadas en la parte posterior de cada imagen. Conocíamos la existencia de estas obras por las menciones que de ellas hace Ricardo Mariátegui Oliva ${ }^{1}$ (1981:58) y por las fotos en blanco y negro publicadas por Guillermo Swayne y Mendoza ${ }^{2}$ donde la calidad de las mismas no permite tener una cabal idea de los méritos plásticos de las pinturas. Allí se muestran con un marco similar al que tienen en la actualidad, piezas modernas que seguramente fueron hechas a imitación de los originales. Las fotos referidas muestran que cada marco tenía un aditamento que formaba un arco de medio punto que, en el caso de él,

1 Mariátegui, Ricardo. 1981. José Gil de Castro. Lima: ediciones La Confianza SA.

2 Swayne y Mendoza, Guillermo.1951. Mis Antepasados. Lima: s/e. 


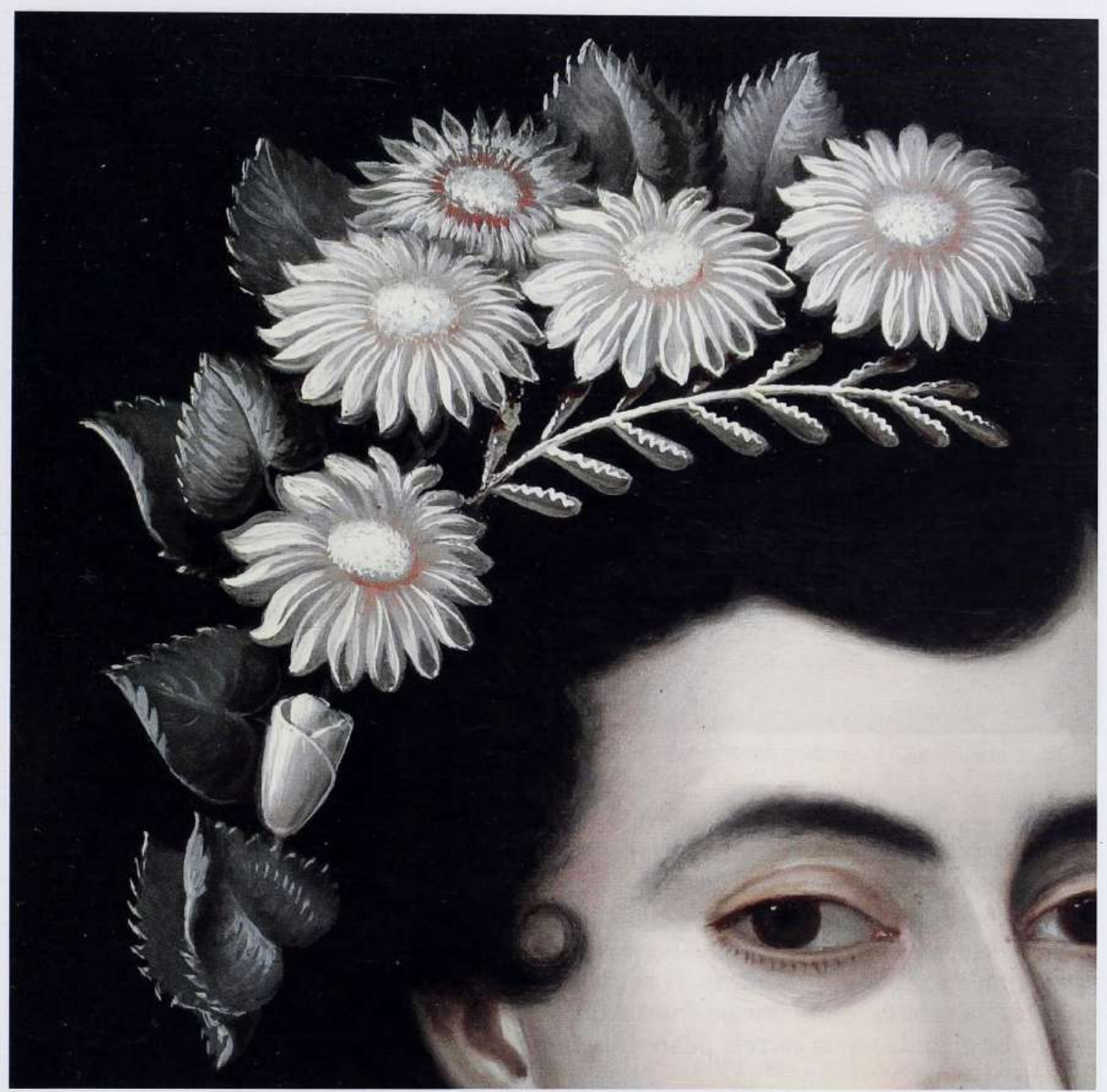

Fig. 4. Manuela Boza y Carrillo de Albornoz (Detalle).

tapaba el cortinaje y parte de los infolios del fondo, y en cuanto al de ella, solo cubría una parte del color neutro sobre el que fue retratada. En Swayne y Mendoza hallamos también un breve comentario sobre ambas pinturas cuando eran propiedad de Francisco Mendoza y Barreda, nieto de la pareja.

El soporte de las pinturas es tela de lino. Su base de preparación es de color anaranjado constituida por los pigmentos blanco de plomo, minio, rojo bermellón y ocres de hierro aglutinados al óleo. La capa de imprimación contiene blanco de plomo con negro de carbón para formar tonalidades de gris, tiza o carbonato de calcio y azul de Prusia igualmente suspendidos en óleo. Los materiales analizados en estas dos pinturas son similares a los hallados en otras obras del mismo pintor que se guardan en colecciones privadas en Lima y en el Museo Nacional de Antropología, Arqueología e Historia del Perú. De este último, se tiene, por ejemplo, dos retratos de Simón Bolívar, uno del Mariscal Luís José de Orbegoso, uno de José Olaya y otro de Pablo Bermúdez, en los que las especificaciones técnicas antes mencionadas son similares a las halladas en los dos lienzos referidos.

Las pinturas que se ocultaban bajo falsas obras del siglo XVIII muestran huellas de haber sido intervenidas. Los exámenes de reflectografía determinan que en ellas no existen 


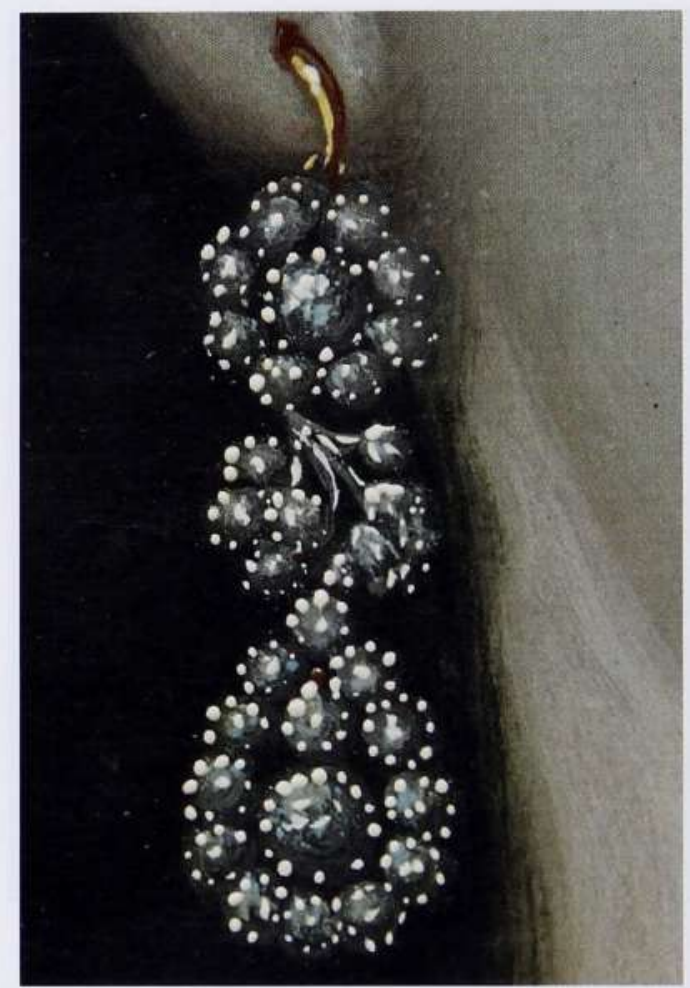

Fig. 5. Manuela Boza y Carrillo de Albornoz (Detalle).

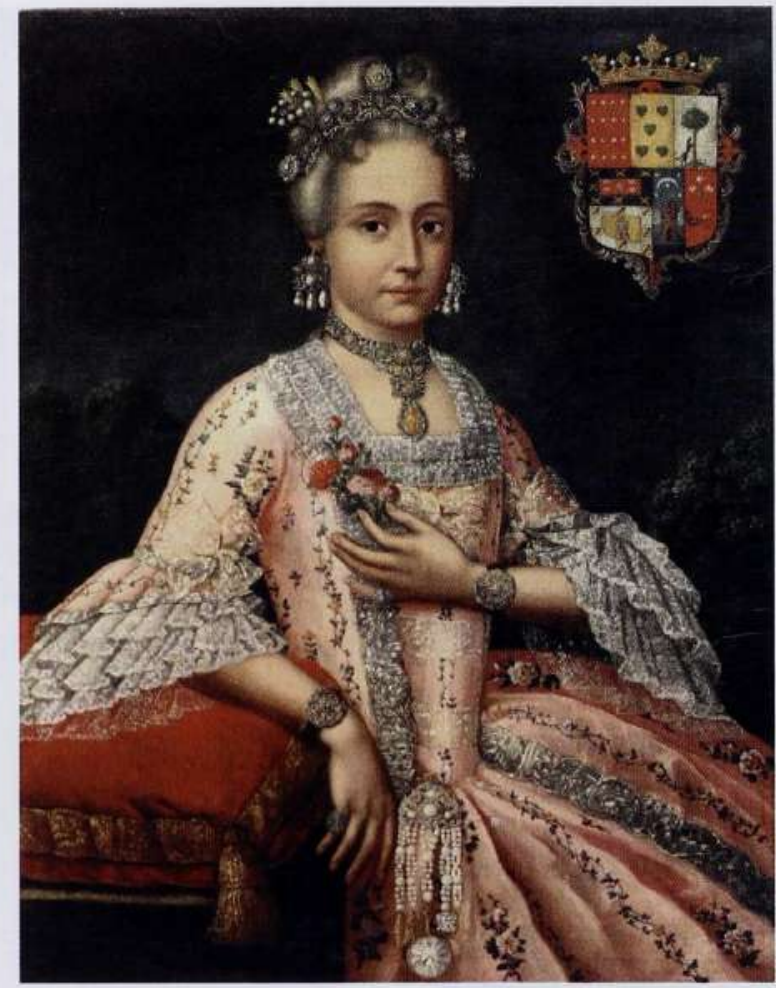

Fig. 6. Condesa de Monteblanco atribuido a Pedro Díaz Díaz. Siglo XVIII.

trazos de dibujos preparatorios, mientras que los de luz ultravioleta demuestran que las reintegraciones cromáticas halladas responden a pocas y reducidas áreas donde la pérdida del color es parcial. Éstas se encuentran, en el caso de él, en la mano izquierda y en la frente, en una parte del cortinaje, en el sector derecho del conjunto de libros y en una pequeña porción de la mesa. El retrato de ella tiene reintegraciones de color en una parte de la cabeza, en el encaje frontal del vestido, en un dedo de la mano izquierda y, en mayor medida, en la cartela posterior. Ambas pinturas retienen casi la totalidad de su factura original.

Se puede afirmar que se trata, sin duda, de dos magníficas obras, ejecutadas en Febrero de 1837 y que de acuerdo a las leyendas en el reverso de cada una, tienen su origen en un pedido de la pareja al pintor cuando éste contaba con 52 años de edad, según la cronología propuesta por Natalia Majluf ${ }^{3}$. En el retrato de Francisco de Mendoza Ríos y Caballero se lee la siguiente inscripción:

El Sr. Dn. / Franc ${ }^{0}$ de Mendoza Ríos, y / Caballero; Coronel Graduado / de Infantería de Milicias, / y Alcalde Constitucional de / Lima, su PATRIA, dos veses: / Y se hizo retratar en obsequio de su / Esposa, la Sra. Da / Manuela Boza y Carrillo / de Albornoz. / Por José Gil, / En Feb ${ }^{\circ}$. Año de 1837.

Detrás de la tela con el retrato de ella, se tiene lo siguiente:

La / Señora Doña / Manuela Boza y / Carrillo de Albornoz, / Esposa del Sr. Dn. Francisco / de Mendoza / Y se hizo retratar en Lima, su / PATRIA, / Capital del Perú, en obsequio / de su amado esposo: / en Feb ${ }^{\circ}$. Del año de / 1837 / por/ José Gil.

3 Majluf, Natalia. 2001. Arte Republicano y Contemporáneo. En El arte en el Perú. Obras en la colección del Museo de Arte de Lima, L. Fioco, N. Majluf, M. Moreno y E. Paredes (ed.): 127-143. Lima: edición del Museo de Arte de Lima y PROMPERU. 


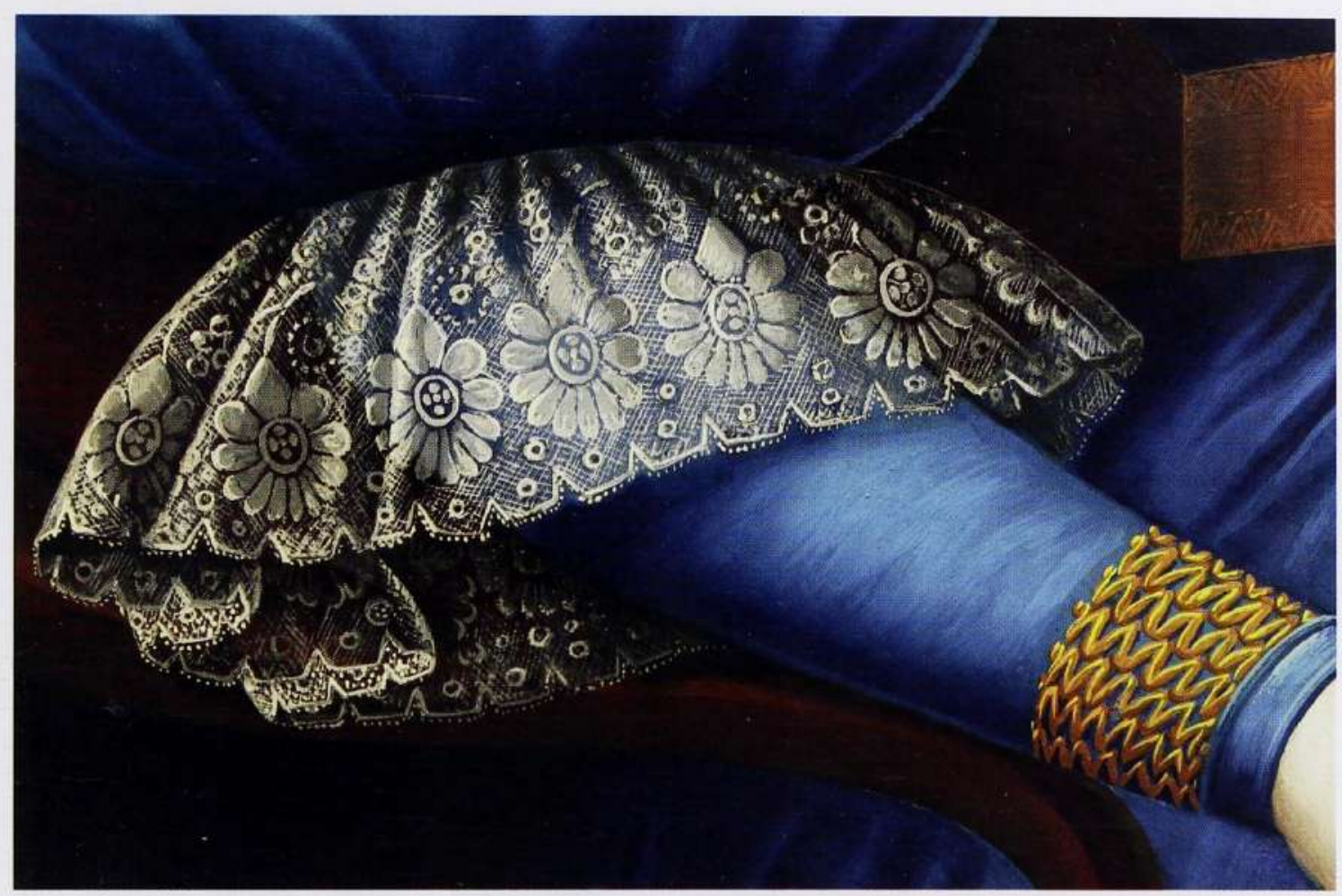

Fig. 7. Manuela Boza y Carrillo de Albornoz (Detalle).

Francisco de Mendoza Ríos y Caballero (1793-1837) fue el hijo mayor de Don Tiburcio Mendoza Ladrón de Guevara Ríos y Caballero, alcalde ordinario de Lima en 1802, cuya familia dio origen a las casas de Aliaga, Presa, Santa Cruz y Padilla. En 1820 fue regidor constitucional y juez de aguas ${ }^{4}$ y, al igual que su padre y sus abuelos antes que él, Francisco también fue alcalde Lima en 1823, 1824, 1825 y $1833^{5}$. Murió en Octubre del año 1837 , poco antes de cumplir 44 años de edad.

Manuela Boza y Carrillo de Albornoz, nacida en Diciembre de 1803, vivió hasta el año 1883. Su retrato, el mismo que aquí se reproduce, fue comentado por Swayne y Mendoza en función del "....adorno de flores de brillantes que se indica en el Recibo de Dote" (1953: 96,97). Efectivamente, dicho adorno que luce en la cabeza con el que el pintor la retrató a los 34 años de edad (Fig.4) es el mismo que se menciona como parte de los bienes que llevó al matrimonio, en Febrero de 1823. La relación de éstos, publicada por el antedicho autor, da cuenta del valor en pesos al que ascendía la cantidad de dinero en metálico, bienes inmuebles, joyas, esclavos y obsequios recibidos con ocasión de su boda. En el rubro de las joyas, se incluye anillos con brillantes, aretes con diamantes (Fig.5), collares de perlas y “...un par de flores de cabeza con veinticuatro Diamantes Tablas mayores y los diez chicos Rosas, y dos topacios ovalados en los medios...", entre otras alhajas ${ }^{6}$. Se advierte así que el gusto por las joyas que las limeñas de clase alta tenían, visible en tantos retratos femeninos firmados por Cristóbal Lozano, Cristóbal de Aguilar o Pedro Díaz (Fig.6), viene de épocas anteriores y que en el siglo XIX era una moda todavía vigente, tal como el propio José Gil de Castro nos lo muestra en sus obras.

4 Mendiburu, Manuel de. 1933. Diccionario Histórico Biográfico del Perú, Tomo VIII, segunda edición, Lima: librería e imprenta Gil S.A.

5 Swayne y Mendoza, Op. Cit.

6 Ibidem, pp. 96 y 97. 


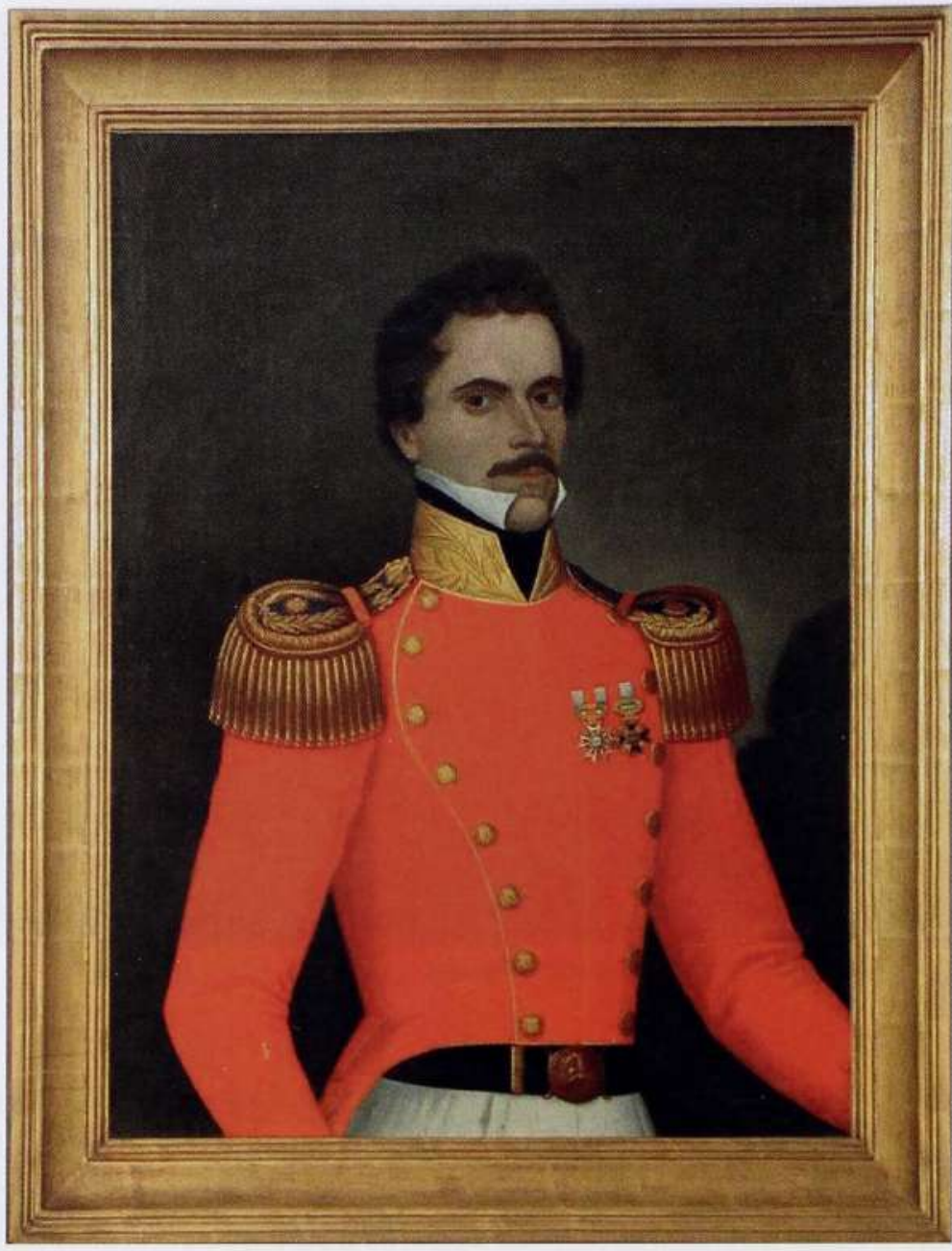

Fig. 8. Coronel Clemente Ramos. Pintado por José Gil de Castro.

Los retratos de Francisco de Mendoza Ríos y Caballero y de Manuela Boza y Carrillo de Albornoz son dos de los mejores trabajos del pintor. Confirman su habilidad en la representación de texturas y en la definición clara y precisa de los detalles (Fig.7). Del mismo modo, su manejo del color le permite elaborar esquemas a base de tonos cálidos y armónicos, o sugerir volúmenes mediante un suave claroscuro, como en los retratos del coronel Clemente Ramos (Fig. 8) y de Don Diego de Bilbao, pertenecientes a la pinacoteca del desaparecido Banco Wiese, o bien, ejecutar un trabajo con tonos fríos y ocres oscurecidos, como los referidos de Francisco y Manuela, en los cuales el rojo intenso de la cubierta de la mesa junto a la que él se ubica y del tapiz de la silla con brazos sobre la que ella se sienta, así como sus accesorios decorativos dorados, constituyen puntos de ruptura de un discurso cromático en el que domina la gama de azules, grises y blancos. Con estas herramientas, la esquematización formal de sus retratos, herencia de su formación tardo colonial, se convierte en una elaboración preciosista que refleja su visión interpretativa y embellecedora de la realidad. 